\title{
The Coronary Sinus Reducer - Clinical Evidence and New Perspectives On An Emerging Tool in the Treatment of Refractory Angina
}

\author{
Carlo Zivelonghi and Stefan Verheye \\ Cardiovascular Center Zeikenhuisnetwerk Antwerpen (ZNA)-Middelheim, Antwerp, Belgium
}

DOI: https://doi.org/10.17925/HI.2020.14.1.29

$\mathrm{T}$ he coronary sinus reducer represents an emerging therapeutic option for patients suffering from chronic refractory angina. Current data indicate that the population suffering from angina symptoms despite maximal medical therapy and maximal achievable revascularisation - surgical or percutaneous - is constantly increasing. Also, the clinical outcome for these patients is strongly affected by the lack of adequate treatment, the occurrence of adverse events and the need for repeated hospitalisation. Growing evidence supports the clinical benefits of the coronary sinus reducer in relieving angina symptoms in this specific population, with emerging evidence of reduction in myocardial ischaemia following the implantation of the coronary sinus reducer. In this review, we provide an up-to-date description of the role of this relatively new device in the treatment of refractory angina, focusing not only on symptom relief but also on the increasing data that supports objective improvements in myocardial ischaemia.

\section{Keywords}

Refractory angina, coronary sinus reducer, coronary interventions

Disclosures: Stefan Verheye is a consultant for Neovasc Inc. Carlo Zivelonghi has no financial or non-financial relationships or activities to declare in relation to this article.

Review Process: Double-blind peer review. Compliance with Ethics: This article involves a review of literature and does not report on new clinical data, or any studies with human or animal subjects performed by either of the authors.

Authorship: Both named authors meet the criteria of the International Committee of Medical Journal Editors for authorship for this manuscript, take responsibility for the integrity of the work as a whole and have given final approval for the version to be published.

Access: This article is freely accessible at touchCARDIO.com (c) Touch Medical Media 2020.

Received: 12 May 2020

Accepted: 23 June 2020

Published Online: 4 August 2020

Citation: Heart International. 2020;14(1):29-33

Corresponding Author: Stefan Verheye,

Interventional Cardiology, Cardiovascular Center,

ZNA Middelheim, Lindendreef 1, 2020 Antwerp, Belgium.

E: stefan.verheye@gmail.com

Support: No funding was received for

the publication of this article.
Refractory angina pectoris is a chronic disabling condition affecting an increasing number of patients (10-15\%) with severe ischaemic heart disease. ${ }^{1}$ It is generally defined as the presence of debilitating angina due to severe and/or diffuse coronary artery disease (CAD), despite optimal medical therapy and with no option for further percutaneous or surgical revascularisation procedures. As shown in previous studies, refractory angina has a significant impact on a patient's quality of life, with a high incidence of hospitalisations, frequent episodes of depression and anxiety due to the symptoms, and a higher fatality rate compared with patients who successfully undergo revascularisation procedures for chronic ischaemic heart disease..$^{2-5}$ Of note, the only treatment option reserved for these relatively young patients (60-65 years) is limited to classical anti-ischaemic drugs. ${ }^{6}$

For physicians, this 'no-option'-labelled population represents a therapeutic challenge due to their high complexity and heterogeneity. ${ }^{7 .}$ Most are not good candidates for revascularisation - surgical or percutaneous - because of the technically high complexity of such interventions, which is often due to extreme evolution of atherosclerotic involvement of the coronary arteries (including chronic total occlusions or diffuse disease) or even because of repeated failure of previous revascularisation interventions. Some patients even remain symptomatic for angina despite successful revascularisation procedures; this is referred to as 'residual' or 'persistent' angina and

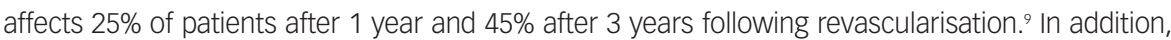
an emerging group of refractory angina patients are affected by 'micro-vascular angina' with no revascularisation options at all, considering the absence of significant epicardial coronary stenosis.?

The various clinical conditions, the specific presentations and the pathophysiological basis of this clinical entity are the foundation of the difficulties in finding an efficient therapeutic strategy to suit all these patients. ${ }^{10-12}$ Moreover, the healthcare costs associated with refractory angina are consistently increasing, which supports the need for expanding strategies in the treatment of this condition. ${ }^{12}$ Currently, this is mainly limited to traditional anti-anginal medications and lifestyle changes. ${ }^{13-15}$

A novel therapeutic option for these patients is represented by the coronary sinus reducer (CSR). This device received CE approval in November 2011.16 The first basis of this technique comes from the experience of heart surgeons, Beck and colleagues, in the early 1950s.17,18 They performed surgical narrowing of the main cardiac vein to cause redistribution of myocardial blood flow into ischaemic territories and the results at the time were gratifying. Despite these promising results, the approach was largely abandoned due to the rapid development of surgical and percutaneous revascularisation procedures. However, interest was renewed in recent years as the number of complex patients suffering from refractory angina (undergoing multiple revascularisation procedures, with multiple comorbidities and complex lesions) started to increase. 
Figure 1: The coronary sinus reducer device

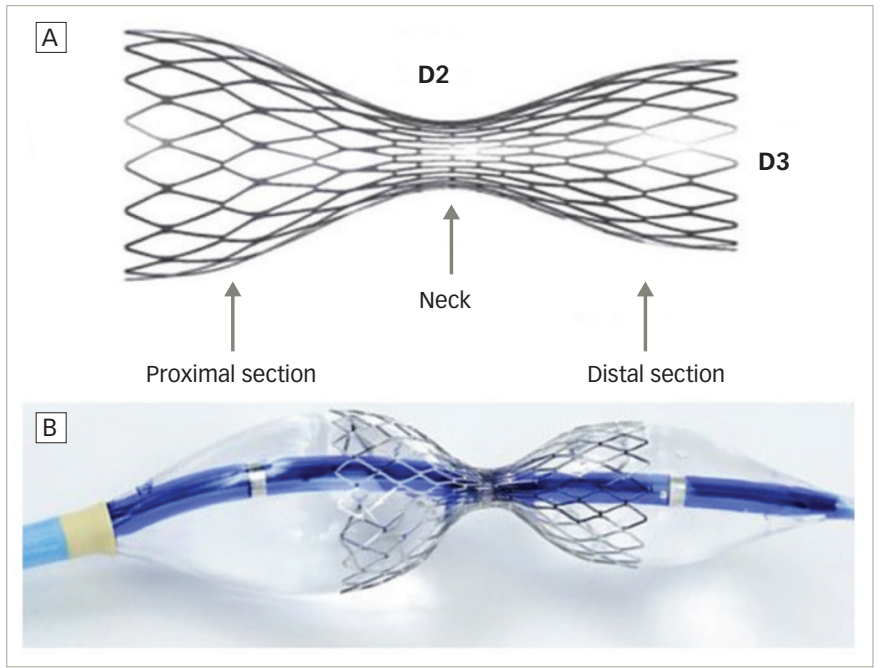

A. Expanded device (note the hourglass shape); B. Expanded device mounted on the delivery balloon.

$D=$ diameter.

Consequently, the CSR has been designed and introduced into clinical practice as an alternative treatment for such patients. 19,20 $^{2}$

\section{Device and procedural characteristics}

The CSR consists of a stainless-steel mesh pre-mounted on an hourglass-shaped balloon catheter, intended to be percutaneously implanted into the coronary sinus (CS) to generate a focal narrowing and to increase coronary venous pressure (Figure 1). It is available in a single size, which is adaptable to the tapered anatomy of the CS by the balloon inflation pressure (diameter $3 \mathrm{~mm}$ in the mid-portion and $7-13 \mathrm{~mm}$ at both ends).

The implantation procedure is performed percutaneously via the right jugular vein. At first, a 6 French (F) diagnostic catheter is used to reach the right atrium (where invasive central venous pressure is recorded) and to selectively engage the CS, where contrast is injected to assess the vessel anatomy. Then, a 9F guiding catheter is exchanged over the wire to be positioned distally in the CS, and the CSR is advanced to the targeted implantation site. Once the CSR reaches the implantation site, the guiding catheter is retracted to expose the device, allowing the balloon to inflate and the CSR to expand. After deflation, the balloon catheter is retrieved and a final angiogram evaluates the positioning, confirms the narrowing and excludes any complications such as perforation or migration (Figure 2). Dual antiplatelet therapy with aspirin and clopidogrel is generally recommended for 1 month after the implantation. ${ }^{21}$

\section{Insights on the mechanism of action}

The first descriptions of the possible mechanisms of action of the CSR device were reported by Camici and Fillipo ${ }^{7}$ and later by Banai and colleagues. ${ }^{19}$ In normal conditions, when the heart is exposed to exercise, the sympathetic-mediated vasoconstriction of the sub-epicardial vessels leads to increased blood flow to the sub-endocardial layers. ${ }^{22}$ This mechanism becomes impaired in the presence of obstructive CAD. ${ }^{23}$ Moreover, the high left ventricular end-diastolic pressure commonly associated with ischaemic heart disease directly affects the myocardial wall kinetics, resulting in a substantial increase in coronary flow resistance and sub-endocardial ischaemia.

A focal narrowing of the CS in the setting of ischaemic myocardium raises the pressure in the venous drainage system, inducing dilatation of arterial capillaries and reduction of flow resistances; this eventually leads to a redistribution of blood from the less ischaemic sub-epicardium to the more ischaemic sub-endocardium. ${ }^{24,25}$ Promising results were first described in animal models. ${ }^{26-30}$ In humans, the beneficial effects of the CSR start once the endothelialisation of the device has reached a certain level, which is approximately $1-3$ months after implantation. ${ }^{19,24}$

\section{Patient selection and contraindications}

Similar to all invasive procedures, adequate patient selection is essential to obtain clinical benefits and avoid unnecessary interventions followed by treatment failure. The clinical characteristics of good candidates for CSR implantations are:

- the presence of angina (Canadian Cardiovascular Society [CCS] class II-IV);

- documented myocardial ischaemia with non-invasive modalities involving the left coronary artery territory;

- optimal antianginal medications; and

- a lack of alternatives for surgical or percutaneous revascularisation, which must be decided by the heart team. ${ }^{21}$

Patients without documented myocardial ischaemia, or ischaemia limited to the right coronary artery (RCA) territory, have been shown to be less than ideal candidates. ${ }^{21}$ Of note, venous drainage of the RCA generally comes from the middle cardiac vein and drains into the proximal CS (close to the ostium). The device is not recommended in patients with advanced heart failure and systolic dysfunction (ejection fraction $<30-35 \%$ ), where alternative therapies (e.g. cardiac resynchronisation therapy) should be considered, nor in patients with mean right atrium pressure $>15 \mathrm{mmHg}$, or those who have recently (within $<3$ months) had percutaneous coronary intervention or a coronary artery bypass graft, where the benefits of the revascularisation procedures are awaited. ${ }^{21}$

\section{The non-responders - new evidence}

Clinical benefits, in terms of symptom relief, have been consistently observed across studies in approximately $70-80 \%$ of patients receiving the $\mathrm{CSR}_{i}^{21}$ however, the reason for the lack of efficacy in the remaining percentage is still under investigation. As discussed, elements such as angina related to ischaemia on the right coronary territory, coexisting heart failure or chest pain in the absence of documented ischaemia may play a role in these cases. ${ }^{21,31}$

More recently, physiological investigations also have been conducted to further explore possible explanations for the lack of efficacy of the CSR. One of these investigations is based on the possible presence of a well-developed alternative coronary venous drainage system. ${ }^{32}$ More specifically, the investigators measured the pressure distally to the CSR implantation site at the moment of device inflation - a coronary sinus wedging pressure. In ideal conditions, a 'ventricularisation' of the pressure wave is observed, supporting the lack of alternative venous drainage systems and, as such, is associated with significant clinical benefits. According to the authors, absence of this change in pressure-wave shape may be associated with lack of clinical improvements. As the authors suggest, measuring the CS wedge pressure during balloon inflation could help to detect non-responders. A recent report from our group also hypothesised that incomplete endothelialisation of the device, even several months after implantation, could be responsible for a lack of pressure gradient across the CSR itself, resulting in an absence of clinical benefits that were otherwise expected. ${ }^{33}$

\section{Procedural complications}

Very low rates of procedural complications have been reported so far during CSR implantation. ${ }^{26,39}$ Consequently, this is considered a very safe 

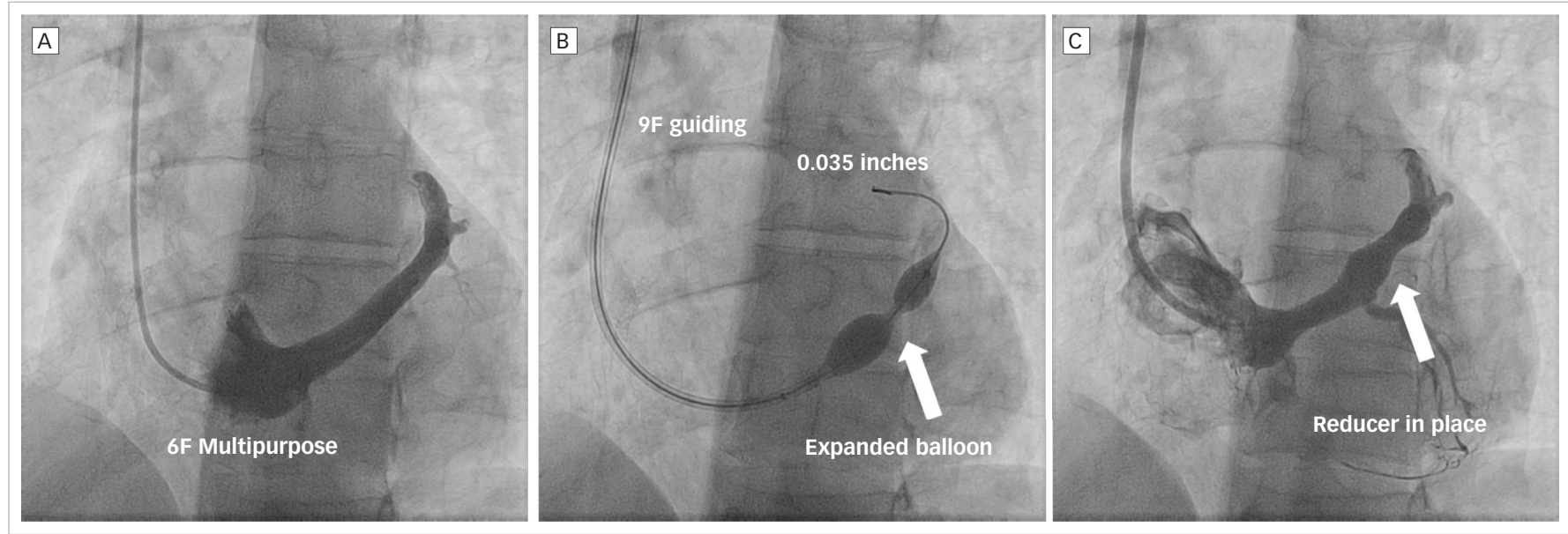

A. Basal angiography of the coronary sinus; B. Implantation of the coronary sinus reducer in the desired target; C. Final angiographic control with the device in place. $F=$ French

intervention; ${ }^{21}$ however, possible complications may include CS dissection during catheter or wire manipulation and direct or late device migration.

In a recent report, the authors described for the first time a perforation of the CS, which occurred during CSR implantation. ${ }^{34}$ After the implantation of the device and balloon retrieval, the control angiogram showed contrast extravasation reaching the left atrium. The patient remained haemodynamically stable throughout the procedure; protamine sulphate was administered and a semi-compliant balloon inflated at the perforation site for 5 minutes, resulting in sealing of the perforation. No pericardial effusion was evident at echocardiographic control and the patient was discharged 2 days later. ${ }^{34}$

A multicentre international collaboration to assess the incidence of procedural complications, their management and clinical implications in a large study population ( $>500$ patients) - the RESOURCE study - is ongoing, headed up from the San Raffaele Hospital, Milan, Italy.

\section{Efficacy and performance in clinical studies}

After the first pre-clinical experiments in swine models supporting the safety and feasibility of CSR implantation, ${ }^{21,27,35}$ further studies in humans investigated the efficacy of this device in improving quality of life and myocardial ischaemia in patients with refractory angina (Table 1). . $92,24,36-43$

CSR implantation was investigated for the first time in a non-randomised prospective study in 15 patients. ${ }^{19}$ Procedural success was complete and complications were absent. At clinical follow-up, a significant reduction in CCS class was registered in the majority of the cases (85\%). Additional investigation for myocardial ischaemia, as assessed with dobutamine stress-echocardiography at 6 months, disclosed a significant reduction of extent and severity in 8 out of 13 patients. Other objective improvements were also documented with thallium single-photon emission computed tomography. ${ }^{19}$ Similar clinical improvements were observed in $85 \%$ of the subjects enrolled at two sites in Antwerp, Belguim and Tel Aviv, Israel. Significant improvements in CCS class were documented across the study population (mean CCS score reduced from $3.3 \pm 0.6$ at baseline to $2.0 \pm 1.0$ at 6 months, $\mathrm{p}<0.01){ }^{44}$ The authors also reported significant improvements in the wall motion severity index during stress, as assessed by dobutamine echocardiography at the 6-month follow-up. In addition, improvements in other scores of myocardial perfusion during thallium stress scans indicated an overall improvement in the extent and severity of the ischaemic segments after CSR implantation. ${ }^{44}$

The cornerstone of the clinical evidence supporting the adoption of CSR is represented by the Coronary Sinus Reducer for Treatment of Refractory Angina (COSIRA) trial. ${ }^{24}$ In this double-blind, randomised, sham-controlled trial, 11 clinical centres were involved. A total of 104 patients were randomised in a 1:1 ratio to undergo either implantation of the study device or a sham procedure. The primary endpoint of the study was the reduction in angina symptoms evaluated by CCS score: this was observed in $71 \%(37 / 52)$ of patients in the treatment and $42 \%(22 / 52)$ of the control group ( $p=0.003)$. Furthermore, an improvement of two or more CCS classes was registered in 35\% (18/52) of the patients in the treatment group versus $15 \%$ (8/52) of the control group $(p=0.02)$. These significant benefits were also confirmed in the quality of life assessment as provided by the Seattle Angina Questionnaire (SAQ). ${ }^{24}$

Subsequently, multiple prospective and retrospective registries were carried out to further confirm the clinical benefits observed in the COSIRA trial - all with consistent results. ${ }^{36-38}$ The largest of these was the multi-centre REDUCE clinical registry. ${ }^{39}$ This observational registry included data from 141 consecutive patients undergoing CSR implantation at three centres (Antwerp Cardiovascular Center, Belgium; San Raffaele Hospital, Milan, Italy; and Tel-Aviv Medical Center, Israel). Patients suffering from chronic angina (defined as CCS classes II-IV) with documented CAD, no option for further revascularisation and with evidence of myocardial ischaemia by non-invasive tests received the study device. No peri-procedural complications occurred; consistent with the results of the COSIRA trial, significant improvements in mean CCS class and all SAQ items were observed. The number of anti-ischaemic drugs prescribed was significantly reduced during a median follow-up of 14 months. Of special interest, in a sub-group of patients undergoing ischaemia evaluation with non-invasive imaging techniques before and after CSR implantation, the authors were also able to show a significant reduction in the extent of both ischaemia and inducible ischaemia, which were evaluated with myocardial scintigraphy and dobutamine stress echocardiography, respectively. ${ }^{39}$

At present, only observational registries have reported data about objective reduction of myocardial ischaemia following CSR implantation; however, the body of evidence in this regard is increasing. ${ }^{39 \cdot 41}$ 
Table 1: Clinical improvements after coronary sinus reducer implantation in currently available clinical studies

\begin{tabular}{|c|c|c|c|c|c|}
\hline Authors & Type of study & $\begin{array}{l}\text { Patients } \\
\text { (n) }\end{array}$ & Endpoint & $\begin{array}{l}\text { CCS score } \\
\text { improvement }\end{array}$ & Other findings \\
\hline Banai et al. $2007^{19}$ & First-in-man & 15 & Safety-feasibility & $\begin{array}{l}\text { Mean reduction: } \\
-1.4\end{array}$ & $\begin{array}{l}\text { Reduction in ischaemia during dobutamine echocardiography } \\
\text { and thallium single-photon emission computed tomography }\end{array}$ \\
\hline Verheye et al. $2015^{24}$ & $\begin{array}{l}\text { Double-blind } \\
\text { randomised } \\
\text { sham-control trial }\end{array}$ & 104 & $\begin{array}{l}\text { CCS class } \\
\text { improvement } \\
\text { ( } \geq 2 \text { points) }\end{array}$ & $\begin{array}{l}\text { Mean reduction: } \\
-1.1\end{array}$ & $\begin{array}{l}\text { Primary endpoint occurred in } 35 \% \text { of patients in the } \\
\text { CRS-treated group versus } 15 \% \text { of the control group ( } p=0.02 \text { ); } \\
\text { CCS improvement of } \geq 1 \text { class occurred in } 71 \% \text { versus } 42 \% \\
\text { respectively ( } p=0.003 \text { ). Significant improvement in SAQ score }\end{array}$ \\
\hline Abawi et al. $2016^{36}$ & $\begin{array}{l}\text { Single-centre } \\
\text { registry }\end{array}$ & 23 & Procedural safety & $\begin{array}{l}\text { Any reduction in CCS } \\
\text { class observed in } 74 \% \\
\text { of patients }\end{array}$ & - \\
\hline Giannini et al. $2018^{37}$ & $\begin{array}{l}\text { Single-centre } \\
\text { registry }\end{array}$ & 50 & Safety/efficacy & $\begin{array}{l}\text { Mean reduction: } \\
-1.3\end{array}$ & $\begin{array}{l}\text { Significant improvement in SAQ score and 6-minute walking } \\
\text { test }\end{array}$ \\
\hline Konigstein et al. $2018^{38}$ & $\begin{array}{l}\text { Single-centre } \\
\text { registry }\end{array}$ & 48 & Clinical Improvement & $\begin{array}{l}\text { Mean reduction: } \\
-1.4\end{array}$ & $\begin{array}{l}\text { Significant improvements in exercise capacity, 6-minute } \\
\text { walking test distance, left ventricle ejection fraction under } \\
\text { stress and wall motion score index }\end{array}$ \\
\hline $\begin{array}{l}\text { Giannini et al. } 2018^{39} \\
\text { (REDUCE study) }\end{array}$ & $\begin{array}{l}\text { Multi-centre } \\
\text { registry }\end{array}$ & 141 & $\begin{array}{l}\text { CCS class and SAQ } \\
\text { score improvement }\end{array}$ & $\begin{array}{l}\text { Mean reduction: } \\
-1.4\end{array}$ & $\begin{array}{l}\text { Significant improvement in SAQ score and significant } \\
\text { reduction in anti-angina drugs prescribed }\end{array}$ \\
\hline Giannini et al. $2019^{40}$ & $\begin{array}{l}\text { Single-centre } \\
\text { study }\end{array}$ & 15 & $\begin{array}{l}\text { Perfusion parameters } \\
\text { at CMR imaging }\end{array}$ & $\begin{array}{l}\text { Any reduction in CCS } \\
\text { class observed in } 87 \% \\
\text { of patients }\end{array}$ & $\begin{array}{l}\text { Significant improvement of myocardial perfusion parameters } \\
\text { as investigated with CMR imaging }\end{array}$ \\
\hline Zivelonghi et al. $2020^{41}$ & $\begin{array}{l}\text { Multi-centre } \\
\text { registry }\end{array}$ & 37 & $\begin{array}{l}\text { Oxygen kinetics at } \\
\text { CPET }\end{array}$ & $\begin{array}{l}\text { Mean reduction: } \\
-1.6\end{array}$ & $\begin{array}{l}\text { Significant improvement in effort tolerance (workload }+34 \%) \\
\text { and maximal oxygen uptake in cardiopulmonary exercise test }\end{array}$ \\
\hline Giannini et al. $2017^{42}$ & $\begin{array}{l}\text { Multi-centre } \\
\text { registry }\end{array}$ & 8 & $\begin{array}{l}\text { CCS class and SAQ } \\
\text { score improvement }\end{array}$ & $\begin{array}{l}\text { Mean reduction: } \\
-1.5\end{array}$ & $\begin{array}{l}\text { Significant improvement in CCS class and SAQ score in } \\
\text { patients with microvascular angina }\end{array}$ \\
\hline Zivelonghi et al. $2020^{43}$ & $\begin{array}{l}\text { Multi-centre } \\
\text { registry }\end{array}$ & 205 & $\begin{array}{l}\text { CCS class } \\
\text { improvement }\end{array}$ & $\begin{array}{l}\text { Mean reduction: } \\
-1.2\end{array}$ & $\begin{array}{l}\text { Significantly greater CCS class improvement in patients with } \\
\text { chronic total occlusions }\end{array}$ \\
\hline
\end{tabular}

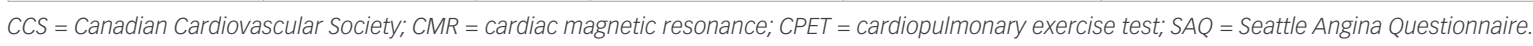

In a single-centre Italian study, ${ }^{40} 15$ patients undergoing CSR implantation were investigated with cardiac magnetic resonance (CMR) before the procedure and 4 months after. Symptom relief was observed in 13 patients (87\%). As a main finding, analysis of the CMR images showed that median per-patient ischaemic burden reduced from 13\% to $11 \%(p=0.0092)$ and the number of segments with inducible perfusion defect from 6 (interquartile range [IQR] 2-9) to 5 (IQR 2-6; $\mathrm{p}=0.0138$ ). The overall number of segments with inducible perfusion defect reduced from $92 / 240$ (38\%) to 69/240 (29\%; $p<0.001$, by logistic mixed-effects model). Reducer implantation led to a significant increase in the transmural myocardial perfusion reserve index (MPRl; $p<0.001$ ), driven by the ischaemic segments (predicted $\triangle \mathrm{MPRI}=0.355$ in segments with baseline MPRI $<1.3$ and $=-0.036$ in segments with baseline MPRI $\geq 1.3$; $p<0.001$ ). This first systematic assessment of myocardial perfusion with CMR provided deep insights into the physiological basis of the CSR mechanisms of action, supporting not only the clinical benefits described so far, but also an objective reduction in myocardial ischaemia. Improvements in myocardial perfusion as investigated with CMR were also shown by Konigstein et al. in a study involving 15 patients undergoing CSR implantation. ${ }^{21}$

Consistent with these results, objective improvements after CSR implantation were investigated by Zivelonghi et al. by means of cardiopulmonary exercise test (CPET). ${ }^{41}$ In this multicentre experience, a total of 37 patients were enrolled in this study, all of which performed a CPET before CSR implantation and at the 6-month follow-up. In fact, significant improvements in objective parameters were observed, with increased effort tolerance (workload: + 12.9 [+ 34\%]; $68 \pm 28$ W versus $81 \pm 49 \mathrm{~W} ; \mathrm{p}=0.05$ ) and oxygen kinetics as expressed by maximal oxygen uptake $(+0.97 \mathrm{~mL} / \mathrm{kg} / \mathrm{min}$ [+ 11.3\%], $12.2 \pm 3.6 \mathrm{~mL} / \mathrm{kg} / \mathrm{min}$ at baseline versus $13.2 \pm 3.7 \mathrm{~mL} / \mathrm{kg} / \mathrm{min} ; \mathrm{p}=0.026$ ) and maximal oxygen uptake at anaerobic threshold $(9.84 \pm 3.4 \mathrm{~mL} / \mathrm{kg} / \mathrm{min}$ versus $10.74 \pm 3.05 \mathrm{~mL} / \mathrm{kg} / \mathrm{min}$; $\mathrm{p}=0.06$ ). These results demonstrated objective reduction in myocardial ischaemia after CRS implantation, providing a strong physiological base underlying its clinical efficacy, with potential impact on long-term clinical outcomes.

So far, the evidence supporting the use of this device is limited to one phase II randomised clinical study and multiple registries. Further studies are now ongoing to evaluate the benefits of this device in larger sample sizes. A multi-centre observational clinical study (REDUCER-l; ClinicalTrials.gov identifier: NCT02710435) will include 400 patients from 40 centres in Europe with a 5-year extended follow-up; a phase III multi-centre, randomised, double blinded, sham-controlled clinical trial (COSIRA II) will enrol 380 patients from more than 30 centres across North America.

\section{Coronary sinus reducer efficacy in special settings}

Treatment of refractory angina due to microvascular dysfunction by implantation of a CSR received some recent attention. The first available and preliminary data came from Milan where 8 patients with refractory angina and a lack of significant coronary stenosis underwent CSR implantation for the treatment of microvascular angina. ${ }^{42}$ At early follow-up, improvement in CCS class was observed in 7 patients. At the 1-year follow-up, this benefit was maintained in 3 of the 5 patients assessed. In these 3 patients, dipyridamole CMR with MPRI calculation were found to have an increased MPRI of the ischaemic segments 
and an increased mean MPRI of the whole ventricle after intervention. Despite the very limited number of patients enrolled in this analysis, these results suggest that even patients suffering from microvascular refractory angina may benefit from improved myocardial perfusion, with a pattern similar to those with documented CAD and no options for further revascularisation. To the authors' knowledge, additional studies are now ongoing to further investigate the benefits of this device in this specific context.

Another setting of growing interest currently is represented by refractory angina in patients with non-revascularised chronic total occlusion (CTO) lesions. In a recently published multi-centre study, Zivelonghi et al. ${ }^{43}$ retrospectively investigated the clinical benefits observed in patients with documented CTO lesions undergoing CSR implantation. In more than 200 patients treated with the CSR, nearly $50 \%$ had a documented non-revascularised CTO lesion at coronary angiogram (excluding CTOs with a patent graft connected to the CTO vessel distally to the occlusion). The main finding was that a significantly greater improvement in CCS class 6 months after implantation was observed in the CTO group compared with the non-CTO group ( $81 \%$ versus $66 \%$, respectively; $p=0.03$ ). In the original animal experiments by Fedele et al. and Toggart et al., treatment success (reduction of myocardial ischaemia) by CS obstruction was dictated by the presence or absence of coronary collateral circulation. ${ }^{45,46}$ In fact, in the absence of collateral circulation, CS obstruction had no effect on the reduction of ischaemia. In contrast, the higher the degree of collateral circulation, the higher the reduction of ischaemia by CS obstruction. ${ }^{45,46}$ As commonly observed in clinical practice, CTO lesions are generally associated with extensive neoangiogenesis and collateral channels. We hypothesise that this side-phenomenon of atherosclerosis could also enhance the flow and pressure redistribution in the coronary epicardial and endocardial vascular bed caused by the CSR implantation.

\section{Conclusions}

Refractory angina represents a constantly increasing clinical entity, considering the improvements in survival of patients with ischaemic heart disease and the ageing of the population. Refractory angina has a relevant impact on the quality of life of the affected patients and is associated with significant healthcare costs. From this perspective, the growing and consistent evidence supporting the benefits of the CSR in this population suggests that this device significantly relieves angina symptoms, may significantly reduce myocardial ischaemia and has an excellent safety profile. It is for these reasons that the CSR should always be considered in this setting, after accurate patient selection according to the appropriate indications.
1. MCGillion M, Arthur HM, Cook A, et al. Management of patients with refractory angina: Canadian Cardiovascular Society/ Canadian Pain Society joint guidelines. Can I Cardiol. 2012;28(Suppl. 2):S20-41.

2. Weintraub WS, Spertus JA, Kolm P, et al. Effect of PCI on quality of life in patients with stable coronary disease. N Eng J Med. 2008;359:677-87

3. Henry TD, Satran D, Hodges JS, et al. Long-term survival in patients with refractory angina. Eur Heart J. 2013;34:2683-8.

4. Povsic TJ, Broderick S, Anstrom KJ, et al. Predictors of long-term clinical endpoints in patients with refractory angina. Clinical endpoints in patients with
J Am Heart Assoc. 2015:4:1-12.

5. Andrell P, Ekre O, Grip L, et al. Fatality, morbidity and quality of life in patients with refractory angina pectoris. Int I Cardio. 2011;147:377-82

6. Brorsson B, Bernstein SJ, Brook RH, Werkö L. Quality of life of patients with chronic stable angina before and four years afte coronary revascularisation compared with a normal population. Heart. 2002;87:140-5.

7. Camici PG, Filippo C. Coronary microvascular dysfunction. N Eng J Med. 2007;356:830-40.

8. Mannheimer $\mathrm{C}$, Camici P, Chester MR, et al. The problem of chronic refractory angina; report from the ESC Joint Study Group on the Treatment of Refractory Angina. Eur Heart 2002:23:355-70

9. Serruys PW. Assessing percutaneous intervention: re-appraising the significance of residual angina. Eurolntervention. 2015:10:1253.

10. Jolicœur EM, Ohman EM, Temple R, et al. Clinical and research issues regarding chronic advanced coronary artery disease part II: trial design, outcomes, and regulatory issues. Am Heart J. 2008;155:435-44.

11. MCNab D, Khan SN, Sharples LD. An open label, single-centre randomized trial of spinal cord stimulation vs. percutaneous myocardial laser revascularization in patients with refractory angina pectoris: the SPiRiT trial. Eur Heart J. 2006;27:1048-53

12. Henry TD, Satran $D$, Jolicoeur EM. Treatment of refractory angina in patients not suitable for revascularization. Nat Rev Cardiol. 2014;11:78-95.

13. Fihn SD, Gardin JM, Abrams J, et al. 2012 ACCF/AHA/ACP/AATS/ PCNA/SCAI/STS guideline for the diagnosis and management of patients with stable ischemic heart disease: a report of the American College of Cardiology Foundation/American the American College of Cardiology Foundation/American Heart Association Task Force on Practice Guidelines, and the American College of Physicians, American Association for Thoracic Surgery, Preventive Cardiovascular Nurses Association, Society for Cardiovascular Angiography and Interventions, and Society of Thoracic Surgeons. J Am Coll Cardiol. 2012;60:e44-164.

14. Kones R. Recent advances in the management of chronic stable angina II. Anti-ischemic therapy, options for refractory angina, risk factor reduction, and revascularization. vasc Health Risk Manag. 2010;6:749-74.

15. Leon MB, Kornowski R, Downey WE, et al. A blinded, randomized, placebo-controlled trial of percutaneous lase myocardial revascularization to improve angina symptoms in patients with severe coronary disease. J Am Coll Cardiol. 2005;46:1812-9

16. Neovasc Inc. Neovasc Inc. receives CE mark for Reducer ${ }^{\mathrm{TM}}$ product to treat refractory angina. 2011. Available at: www.prnewswire.com/news-releases/neovasc-increceives-ce-mark-for-reducertm-product-to-treat-refractoryangina-133802338.html (accessed 20 July 2020).

17. Beck CS, Leighninger DS. Operations for coronary artery disease. J Am Med Assoc. 1954;156:1226-33.

18. Weigel $G$, Kajgana I, Bergmeister $H$, et al. Beck and back: a paradigm change in coronary sinus interventions - pulsatile stretch on intact coronary venous endothelium. J Thorac Cardiovasc Surg. 2007;133:1581-7.

19. Banai S, Ben Muvhar S, Parikh KH, et al. Coronary sinus reduce stent for the treatment of chronic refractory angina pectoris: a prospective, open-label, multicenter, safety feasibility first-in-man study. J Am Coll Cardiol. 2007;49:1783-9.

20. Jolicœur EM, Banai S, Henry TD, et al. A phase II, sham-controlled, double-blinded study testing the safety and efficacy of the coronary sinus reducer in patients with refractory angina: study protocol for a randomized controlled trial. Trials. 2013;14:46.

21. Feigl EO. The paradox of adrenergic coronary vasoconstriction Circulation. 1987;76:737-45.

22. Konigstein M, Giannini F, Banai $\mathrm{S}$. The reducer device in patients with angina pectoris: mechanisms, indications, and perspectives. Eur Heart J. 2018:39:925-33.

23. Crea F, Galassi AR, Kaski JC, et al. Effect of theophylline on exercise-induced myocardial ischemia. Lancet. 1989:333:683-6.

24. Verheye $S$, Jolicoeur EM, Behan MW, et al. Efficacy of a device to narrow the coronary sinus in refractory angina. N Eng J Med. 2015;372:519-27.

25. Sato M, Saito T, Mitsugi M, et al. Effects of cardiac contraction and coronary sinus pressure elevation on collateral circulation. Am J Physiol. 1996;271:H1433-40.

26. Ido A, Hasebe N, Matsuhashi H. Coronary sinus occlusion enhances coronary collateral flow and reduces subendocardial ischemia. Am J Physiol Heart Circ Physiol. 2001:280:1361-7.

27. Konigstein M, Shofti R, Schwartz M, Banai S. Coronary sinus reducer for the treatment of chronic refractory angina pectoris - results of the preclinical safety and feasibility study. - resulter of Cardiovasc Interv. 2018:92:1274-82.

28. Gross $L$, Blum L, Silverman $G$. Experimental attempts to increase the blood supply to the dog's heart by means of increase the blood supply to the dog's heart by means
coronary sinus occlusion. J Exp Med. 1937;65:91-108.

29. Rouleau JR, White M. Effects of coronary sinus pressure elevation on coronary blood flow distribution in dogs with normal preload. Can J Physiol Pharmacol. 1985;63:787-97.

30. Mohl W, Glogar DH, Mayr H. Reduction of infarct size induced by pressure-controlled intermittent coronary sinus occlusion. Am J Cardiol. 1984;53:923-8.

31. Gorla R, Giannini F, Bedogni F, De Marco F. Unusual implantation of a coronary sinus reducer in the middle cardiac vein. J Invasive Cardiol. 2018;30:E69-70.

32. Baldetti L, Colombo A, Banai S, et al. Coronary sinus reducer non-responders: insights and perspectives. Eurolntervention.
2018;13:1667-9

33. Zivelonghi $\mathrm{C}$, Vermeersch $\mathrm{G}$, Verheye S, Agostoni P. Incomplete coronary sinus reducer endothelialization as potential mechanism of clinical failure. Cathet Cardiovasc Interv 2019;94:120-2

34. Cortese B, di Palma G, Latini R. Coronary sinus perforation during reducer implantation. Cathet Cardiovasc Interv. 2018;91:1291-3.

35. Banai S, Ben-Muvhar S, Tsehori J, et al. Transcatheter coronary sinus narrowing with the Neovasc Reducer - an alternative sinus narrowing with the Neovasc Reducer - an alternative not candidates for revascularization procedures - a preclinical study. Presented at: 51 st Annual Conference of the Israel Heart study. Presented at: 51 st Annual Conference of the Israel Heart
society in association with the Israel Society of Cardiothoracic Society in association with the Israel
Surgery, Tel Aviv, Israel, 28 April 2004.

36. Abawi M, Nijhoff F, Stella PR, et al. Safety and efficacy of a device to narrow the coronary sinus for the treatment of refractory angina: a single-centre real-world experience. Neth Heart J. 2016;24:544-51.

37. Giannini F, Baldetti L, Ponticelli F, et al. Coronary sinus reducer implantation for the treatment of chronic refractory angina: a single-center experience. JACC Cardiovasc Interv. 2018;11:784-92

38. Konigstein M, Bazan S, Revivo M, Banai S. Coronary sinus reducer implantation improves symptoms, ischaemia and physical capacity in patients with refractory angina unsuitable for myocardial revascularisation: a single-centre experience. for myocardial revascularisation: a sing

39. Giannini F, Baldetti L, Konigstein M, et al. Safety and efficacy of the reducer: a multi-center clinical registry - REDUCE study. Int J Cardiol. 2018;269:40-4.

40. Giannini F, Palmisano $A$, Baldetti $L$, et al. Patterns of regional myocardial perfusion following coronary sinus reducer implantation: insights by stress cardiac magnetic resonance. Circ Cardiovasc Imaging. 2019;12:e009148.

41. Zivelonghi $\mathrm{C}$, Konigstein M, Azzano A, et al. Coronary sinus reducer implantation results in improved oxygen kinetics at cardiopulmonary exercise test in patients with refractory angina. EuroIntervention. 2020;EIJ-D-19-00766.

42. Giannini $F$, Baldetti $L$, lelasi $A$, et al. First experience with the coronary sinus reducer system for the management of refractory angina in patients without obstructive coronary refractory angina in patients without obstructive coronary

43. Zivelonghi $C$, Verheye $S$, Timmers $L$, et al. Efficacy of coronary sinus reducer in patients with non-revascularized chronic total occlusions. Am J Cardiol. 2020;126:1-7.

44. Konigstein M, Meyten N, Verheye S, et al. Transcatheter treatment for refractory angina with the coronary sinus reducer. Eurolntervention. 2014;9:1158-64

45. Fedele FA, Capone RJ, Most AS, Gewirtz H. Effect of pressure-controlled intermittent coronary sinus occlusion on pacing-induced myocardial ischemia in domestic swine. Circulation. 1988:77:1403-13.

46. Toggart EJ, Nellis SH, Liedtke AJ. The efficacy of intermittent coronary sinus occlusion in the absence of coronary artery collaterals. Circulation. 1987;76:667-77. 